\title{
'WHEN YOU WRITE YOU ARE NOT EXPECTED TO COME FROM YOUR HOME': ANALYSING 'FATEFUL MOMENTS' AS A RECLAIMING OF 'SELF' IN A HISTORICALLY WHITE UNIVERSITY
}

\author{
G. Nomdo \\ Language Development Unit: Academic Development Programme \\ Centre for Higher Education Development (CHED) \\ University of Cape Town \\ Cape Town, South Africa \\ e-mail: gideon.nomdo@uct.ac.za
}

\section{ABSTRACT}

Dismal graduation rates amongst black South African university students indicate high levels of academic unpreparedness. Socio-economic circumstances have been cited as core contributing factors in this regard. Adopting a sociological perspective, I argue that not enough attention is given to the emotional trauma experienced by first generation black working class students transitioning into historically white universities. This trauma often translates into an existential crisis where the search for a new sense of self emerges. This article has been developed from my PhD thesis, and describes the struggles accompanying a black student's search for an authentic sense of identity and acceptance. Drawing on a social constructionist model of identity formation, I locate Giddens' (1991) concept of 'fateful moments' as an effective tool for developing deeper insights into black students' perceptions of self. In doing so, I highlight the sensitivities surrounding these students' academic performance. In concluding, I underscore the strong interconnections between a strong sense of self, feeling at 'home' within the institution, and academic success.

Keywords: black student experience, fateful moments, self-identity transformation, reflexivity, institutional culture, higher educational access, authenticity.

\section{INTRODUCTION}

An important goal of South Africa's democracy concerns facilitating and promoting educational access for black people. Higher educational institutions are required by law to be more accommodating of applicants who fall into the 'previously disadvantaged' category, and to assess the types of support that would be required to help these students succeed (Department of Education 1997). In South Africa (SA), the term 'previously disadvantaged' is synonymous with being black. Higher educational institutions have been inclined to homogenise the black student experience without paying much attention to the variations and disparities within the socio-economic and schooling backgrounds, as well as English language proficiencies that exist amongst this group (see Pym and Kapp 2011; and contributions to Pym and Paxton’s 2013 
edited volume). The transition, for example, from a tiny African rural township school to a cosmopolitan urbanised university setting, is one fraught with immense challenges that extend beyond mere academic ability, 'entry points' and 'predictive factors' (Vincent and Idahosa 2014, 1444).

Many higher educational institutions, especially those falling under the category of 'historically white,' struggle to acknowledge and facilitate the transition experiences of their black student intake. Guided by the default position of understanding white student experiences, these institutions have simply operated under the assumption that the majority of black students who come from families which have no higher education tradition, will somehow manage to adapt and succeed at university. The extremely low graduation rates amongst the increasing number of black students, however, indicate that this is not the case (see Scott, Yeld and Hendry's 2007 study). In contexts where white academic achievement is the norm, high failure rates amongst black students reveal that they are ill equipped to deal with the academic demands of university.

In addition, black students from the townships who enter historically white universities also have the arduous task of having to negotiate the dominant culture of that setting, and are often confronted with an institutional ethos which stresses 'the way we do things around here' (Jansen 2004, 1; also see Vincent and Idahosa 2014, 1440-1441 and the 2013 edited publication by Pym and Paxton in which the large disparities between black and white students at a historically white university is made apparent). This adds to black students' sense of isolation and marginalisation, which has placed issues of transformation in higher education firmly under the spotlight, as was recently made evident by the 'Rhodes Must Fall' campaign at the University of Cape Town (UCT) (UCT News 2015) and the formation of 'Open Stellenbosch' at Stellenbosch University (The Daily Maverick 2015). This illustrates that 'Academic culture is not uniformly accessed or experienced' (Read, Archer and Leathwood 2003, 261), a stark reality in SA, a country with one of the highest levels of income inequality in the world. This predicament of black students places severe pressure on tertiary institutions which are being held accountable for low throughput rates (MacGregor 2009; Department of Education 1997) and the slow rate of transformation (see Nkosi's 2015 article on the Higher Education Minister, Blade Nzimande’s, plans to transform universities in the wake of the 'Rhodes Must Fall' and 'Open Stellenbosch’ campaigns).

Many factors come into play when considering the reasons for academic success and failure, not all of which concern intellectual ability. It has been shown, for example, that having a secure sense of identity and feeling comfortable within an academic institution boosts 
students' self-confidence and facilitates their learning (Mann 2008; Reay 2001; Read et al. 2003). After more than twenty years of democracy, many black South African students currently entering higher education find that it is a challenge to feel comfortable and secure in institutions which, historically, were reserved for whites only. A core contributing factor to this is the issue of class. The dominance of middle class institutional values has tended to reduce the sense of acceptance and support experienced amongst working class, non-traditional students (see Zuma's 2013 doctoral study which shows how factors of race and class affect intergroup relations at UCT and how class divisions, even amongst black students, negatively impacts the plight of the working class black student group; also see Luckett and Luckett’s 2009 study on the challenges faced by financially disadvantaged students' in developing agency within the South African higher education setting). Black students attending historically white institutions therefore continue to face various forms of alienation (The Ministerial Committee on Transformation in Higher Education 2008; Kapp 2000; 2001) that profoundly affect the ways in which they construct, manage and negotiate their student identities within these settings. Cornell and Kessi (2016) highlight this as an ongoing issue in their exploration of seven black students' experiences at UCT. The authors suggest that for many black students the struggle for acceptance and recognition within a predominantly white institutional cultural setting remains a challenge. They argue that deficit connotations of blackness continue to persist within the institution, thereby perpetuating the stereotype of black students' academic underperformance. Within this context of alienation, black students' academic success can only be achieved through devising appropriate strategies for resisting the negative representations of blackness. Cornell and Kessi's $(2016,9)$ study is thus a reiteration of the extreme challenges faced by working and middle class black students in their attempts at assimilation into the university context. Students in these situations experience immense pressure being placed on that core component of identity called the 'self'. Giddens (1991) defines the 'self' as a dynamic social entity, which is actively engaged in finding a sense of purpose and location in the world.

In this article, I draw on my doctoral research (Nomdo 2015) to revisit and build upon my earlier analysis of black student identities operating within an equity development programme at UCT (see Nomdo 2006). This has enabled a shift away from my earlier emphasis on discourse to one in which I attempt to unpack what it feels like to be a first generation black working class student struggling to fit into a historically white tertiary institution. In light of recent and ongoing events, such as the 'Rhodes must Fall' and 'Fees must fall' campaigns and the documentary Luister, which captures black experiences at historically white universities, there is clearly a need for this type of investigation. Luister foregrounds student comments, such as 
'I feel like it's wrong to be black. When I'm alone, I sometimes ask myself ... why did God made me black' (Mbatha 2015). In this regard I continue to unpack some of the experiences of Sipho (one of the respondents in Nomdo 2006), to shed light on some of the emotional trauma suffered by black students in their attempts to integrate into the university setting. As an individual case study, Sipho's experience cannot automatically be used to generalise the lived experiences of an increasingly heterogeneous black student population at historically white universities, particularly the black working class. The dynamic nature of human interaction makes this very hard to do. What Sipho's narrative does offer, however, is quite a provocative and raw vignette of university life and the ways in which socio-economic, cultural and racial categories are manifested within that space. So although the issues that Sipho raises and the nature and intensity of his experiences may not be the same for all black working class students, black students may well be able to identify with the types of concerns that Sipho's narrative brings to the fore, such as the racial stereotyping, the feeling of being academically unprepared, feeling dislocated and lost, unwanted, being confronted with one's lack of privilege, status and discomfort, and so forth. In short, Sipho's narrative is about the experience of being black in a setting where white privilege and achievement is the norm. His story, when placed alongside other narratives of black student experiences, can be used to inform the debates about transformation within the current higher education context of discomfort in which we find ourselves. This analysis of Sipho's journey offers insight into the challenges that first generation, working class black students are faced with, and points to some of the hard choices they have to make to maintain a sense of self in their bid to achieve success and recognition. The aim is to show how the traditional university setting creates severe internal conflict by alienating and positioning black students as outsiders (Bangeni and Kapp 2005; Nomdo 2006; 2015; Cornell and Kessi 2016).

There is, however, another aspect of the black student experience that needs to be highlighted here, namely, that these challenges also present these students with opportunities for developing a new and evolving sense of self in their struggles to belong. Students grappling with these contradictions often find themselves at a crossroads, where they are forced to make decisions about how to locate and reconcile their student identities with their continued sense of self in the world. The decisions made in these types of pressure situations can often be quite drastic, and can act as a catalyst for an intense transformation of identity. I suggest that such an identity transformation process can lead to a reclaiming of agency and an affirmation of an individual's status and sense of presence within the institution. Mann $(2008,30)$ emphasises this point by asserting the importance of acknowledging individual student experiences, as it 
'allows insight into the richness and particularity of student experience, whilst ... ensuring that such experience is not lost to silence'. The stance adopted in this study views students' experiences within the academic institution as an essential part of larger social contexts in which learning is viewed 'as a relational process between individual and society' (Packer and Goicoechea 2000, cited in Luckett and Luckett 2009, 470).

\section{FATEFUL MOMENTS: A DISRUPTION OF 'SELF'}

The concept of a 'self' is a valuable and durable component of identity. It is dynamic, adaptable and can even be transformed. The spaces in which acts of self transformation occur are important and signify defining moments in our life histories. Observing these defining moments gives us the opportunity to glimpse the ability of the self to react and absorb change, so as to ensure our continued meaningful participation in the world. The unpacking of these adaptive and resilient mechanisms of the self will provide a basis for the discussion that will take place later, concerning the experiences of Sipho, a black South African student attending a historically white university.

The core analytical tool utilised in this article is drawn from Giddens's (1991) conceptual understanding of 'fateful moments', viewed here as instances of identity transformations (see also Woods' 1993 use of the term 'critical event' as a transformative learning intervention at school level). Giddens (1991) defines fateful moments as those where important decisions affecting one's future need to be made. The consequences of those decisions are of particular importance here. Giddens sums this up as follows:

Fateful moments are times when events come together in such a way that an individual stands, as it were, at a crossroads in his existence; or when a person learns of information with fateful consequences (Giddens 1991, 113).

Furthermore:

Fateful moments are threatening for the protective cocoon which defends the individual's ontological security, because the 'business as usual' attitude that is so important to that cocoon is inevitably broken through (Giddens 1991, 114).

In other words, highly individualised encounters determine the extent of the impact on an individual's ontological security. Giddens's use of the term 'ontological security' is based on Laing's (1960) work in the area of mental health, where he defines ontological security as something an individual possesses when he has '... a sense of his presence in the world as a real, alive, whole, and, in a temporal sense, a continuous person' (Laing 1960 cited in Croft 
2012, 221). Following on from this, is that an individual who lacks ontological security, 'would lack a sense of self and agency, and would be subject to fears, anxiety, and dread' (Croft 2012, 221). Giddens's (1991) concept of 'fateful moments' therefore signals an individual's lack of trust in his or her ability to maintain a 'sense of continuity and order in events' (Giddens 1991, 243). Amongst the examples of what could be classified as fateful moments, he lists: sitting for examinations, agreeing to marry, divorce, hearing the results of a medical examination, and large gambling debt. Giddens asserts that these types of fateful moment 'possibilities' are defined as fateful because of 'their particular relation to risk', since the decisions made at the time are measured against the possibilities for success and error and also the subsequent consequences of these for the individual's life (1991, 113-114).

Fateful moments therefore represent a drastic disruption to the security and continuity of the self. Giddens uses the concept of 'protective cocoon' (1991) to help grasp the nature and impact of that disruption. The protective cocoon houses the self. It strives to maintain and protect the self from any interruptions and risks that could threaten its security and stability in a rapidly changing world. The successful managing of these risks by the protective cocoon is important since it allows the general everyday occurrences in peoples' lives to take on an 'uneventful character' (Giddens 1991, 126) so that a sense of the ordinary can prevail. However, intrusions into that protective barrier do occur, impacting the self, particularly when individuals experience severe emotional turmoil. This constitutes Giddens's notion of a 'fateful moment', and the manner in which such moments penetrate the 'protective cocoon' is indicative of the extent of change that occurs within the individual's sense of self. In such instances the reconstruction of the damaged cocoon is crucial for creating a sense of normality for the continuation of one's identity. Such reconstruction is made possible and maintained through the act of reflexivity in which biographical narratives of the self are rewritten (Giddens 1991).

The probability of gaining a better understanding of the dynamic and resilient capacity of the self, as alluded to above, rests on a particular understanding of the identity transformation process. The stance adopted here operates on the premise that the very idea of a transformation invokes an image of drastic change that alters an individual's personal sense of location and perspective in the world, as well as the nature of intersubjective relations. Contexts in which change occurs are important and impact the ways in which individuals reconstruct a sense of continuation between past, present and future selves. This implies that our experiences are not isolated instances, but form part and parcel of larger discourses in which our identities and our need to feel safe and to belong is not only invested, but also continually challenged. These are important underlying factors and will be used here to inform my analysis of first generation 
university students such as Sipho.

\section{THE SOCIALLY CONSTRUCTED NATURE OF IDENTITY}

The social constructionist tradition has shown how the self is created out of the relationships that exist between entities (Hawkes 1977; Shotter 1993; Terre Blanche and Durrheim1999). Shotter's (1993) analysis identifies elements of differentiation within these relationships. He asserts that despite our participation in 'the same sea of creative interrelational activity' our 'unique' selves are determined by our placements within the 'seascape' (1993, 6). He argues that although these spaces are occupied solely by the individual, they are not neutral spaces, since the individual 'can become, answerable or responsible to others' (which includes those in one's own circle) for occupying certain positions in such spaces (Shotter 1984, cited in Shotter 1993, 6). Within this context one is 'accountable to others', having to 'justify one's actions to them, when challenged' (Shotter 1984, cited in Shotter 1993, 8). What becomes apparent is that over and above one's access to the general 'seascape', the 'seascape' itself is set up in such a way that either limits or facilitates access into it (Shotter 1993, 6). What evolves out of this unequal spread of access is what Shotter (1984, cited in Shotter 1993, 6) calls 'a political economy of developmental opportunities' which impact on how the self is realised. Social class issues have featured prominently in debates around the disproportionate levels of access experienced amongst university students. Read et al. (2003, 262-269) for example, show how the dominance of middle class discourses serves to marginalise non-traditional sectors within education that lack cultural and material capital. It therefore stands to reason that if higher education is viewed as a 'seascape', then issues of ownership, class, access, social redress, accountability and acceptance all become important components of trying to understand black student experiences in SA, particularly non-traditional students who lack the advantage of being historically and culturally located within tertiary settings. But there is also scope within these settings for realising other more positive possibilities of self, a self who is reflexively made to become (as defined earlier) ‘a real, alive, whole, and ... continuous person’ (Laing 1960, cited in Croft 2012, 221).

To illustrate some of the issues raised above I draw on some of Sipho's experiences within the higher education context. Sipho hails from an impoverished rural township setting in the Eastern Cape and has endured many socio-economic hardships. He was accepted into a historically white university located in a leafy suburb of the Western Cape, to pursue a degree in Commerce. For both Sipho and his family a Commerce degree represented the means to a well-paying job which would alleviate their financial strains. Sipho therefore carried the hopes 
and aspirations of his family and community on his shoulders, which he felt at the time, was not a burdensome load to bear. He was excited by the prospect of going to university and confident in his ability to do well. He displayed a seemingly strong sense of self at this point, located in quite a secure protective cocoon; one which is bolstered by his achievements at his township school, the trust placed in his abilities by his teachers and parents, and his own anticipation of success. He found, however, that being away from the familiarity of home and encountering new ways of doing things can be quite overwhelming. He recalled some of the difficulties he encountered when he first arrived at the university:

Before I came to the suburbs it was fine, because it [the township] was all I knew, but now it was like this jump coming over here and living nicely, a hot shower ... now when I have to go home it's a vice versa .... and everything just becomes like a struggle ... and really, the assessment I can make is you realize the imbalance(s) for what they are (Sipho interview).

He recalled another incident shortly after his arrival where his presence outside of the campus grounds was questioned by an on-duty neighbourhood security guard, who wanted to see proof of his student status. He relived the shock he experienced and states:

If I was wearing a suit ... he would not have stopped me because I'm kind of an acceptable citizen ... but because I'm walking at night in ... the suburbs, you're not supposed to be here ... so you get this contradiction about life, how people perceive you ... but what can you do? You just have to live your life (Sipho interview).

This is illustrative of how his perceived status as a stereotypical black working class male (portrayed by popular South African media largely in terms of crime and violence), severely limits and infringes on his access to the middle and upper middle class spaces located just beyond the university borders. This also shows the extent to which popular representations of race and social class act as a gate-keeper and how the disjuncture between conceptions of a township home and a university home impacts the integration of working class blacks into the cosmopolitan university setting. In Sipho's case the intersections of race, gender and class all add to his outsider status in the historically (and still predominantly) white urban setting bordering the university. The township and university settings are worlds apart and illustrate the ways in which socially constructed categories of black identity continue to interact on multiple levels in creating inequality in society (Crenshaw 1995). In the above scenario Sipho's citizenship is questioned. He seems not to possess the appropriate tools that would facilitate access and a sense of belonging in the urban setting. He is therefore filled with an overwhelming sense of unease when his presence in the neighbourhood is questioned. He is forced into silence, 
lacking the conviction and tenacity to challenge the perception that he does not belong in that space. In terms of Giddens's fateful moment analysis, this incident shows how Sipho's 'protective cocoon' is beginning to come under attack, with a small amount of emotional trauma seeping through the cracks to unsettle the stability of the self. We have here the first phase of Sipho's fateful moment, where he encounters the extent to which the concepts of race and class intersect to produce a white, urban, middle class gaze. The latter confronts his township identity, forcing him to acknowledge the extent of his 'othering' in that space. The widening cracks in his protective cocoon expose a sense of self that is beginning to feel increasingly insecure and vulnerable.

\section{A HOMELESS 'SELF'}

Sipho's sense of isolation within the white setting surrounding the university also extended to his experiences within the university, more specifically in the Commerce faculty. He struggled with the academic demands in Commerce, and was left with no other option but to blame his lack of preparation on an inadequate township schooling system, a realisation that was ‘demoralising’ (Pym and Kapp 2011, 6). He was left feeling increasingly traumatised and isolated because of his yearning to find a sense of belonging. This occurred to such an extent that he was forced to confront the consequences of his decision to do Commerce. He admitted to the following:

It was all about getting a degree for a better job, there was an irrelevance in what I was studying ... I remember my first two weeks, in my room, I went to cry, every day, every day, it was painful, you know (Sipho interview).

Sipho's experience is part of what Thaver $(2006,20)$ refers to as 'culture shock', since there is a sharp disjuncture between his 'home culture' and the urbanised university culture. This disjuncture fuels the feelings of 'alienation and estrangement' he encountered in his attempts 'to feel at home' in the Commerce faculty. Sipho 'stands, as stated earlier, at a crossroads in his existence' (Giddens 1991, 113), where his entire world has been cast into turmoil. The extent of Sipho's emotional distress was severe. The feelings of helplessness and engulfment displayed in the above extract, is indicative of his realisation that a degree in Commerce was not only out of his immediate reach, but also something he no longer aspired to. This realisation cast him into a state of detachment from the world, from others, and also from himself. Being confronted with an absence of meaning in his life shattered the remains of his protective cocoon and plunged Sipho into an existential crisis, driving home the essence of what Giddens 
conceptualised as a 'fateful moment' encounter. Sipho's sense of self had moved from a state of increased vulnerability to complete vulnerability, and was now exposed to the harshness of reality without the protective buffering and filtering of its protective cocoon. So while the first phase of Sipho's fateful moment made him aware of his 'otherness' and silenced him, he still at this stage held on to the possibility of claiming a legitimate space and sense of belonging in the Commerce faculty. As such, the first phase of Sipho's fateful moment therefore sets the scene for the final phase of the encounter in the Commerce faculty. This indicates that a fateful moment is not necessarily a once-off event but can present itself as a process. This process is activated by an initial encounter that in turn creates a stimulus for more traumatic encounters, eventually culminating in an existential crisis. The rendering of Sipho's Commerce experience as the final stage of his fateful moment is marked by the severity of the trauma undergone by his sense of self. Sipho's experience of dislocation within this new and alienating university setting is indicative of the extent to which a fateful moment 'can induce a transitional state of detachment from the world, where one loses one's sense of self and where a state of meaninglessness pervades everyday routines’ (Nomdo 2015, 212).

The question of how to deal with the severe disruptions brought about by fateful moments now becomes important. In other words, how is an individual like Sipho able to internalise and process these disruptions so as to realign and save his sense of self from a constant state of confusion? The latter is what Shotter $(1993,19)$ refers to as 'identity crises' and it is beyond this point that Sipho must now move if he wants to reclaim, in the Heideggerian ontological sense, an 'authentic self' (Wheeler 2013). This particular understanding of authenticity relates to the ways in which an individual's established, resilient and autonomous sense of self-identity culminates in a strong feeling of security in the world.

The understanding of a 'fateful moment' outlined here, must therefore, also be viewed in terms of how individuals deal with the life-changing consequences of the choices they make. This radical, transformative dimension in someone's life, which comes about as a result of a traumatic experience, is what makes a 'fateful moment' such a powerful measure of change. Added to this is the ability to be self-reflective, which is an important mechanism for managing the process of change (Giddens 1991).

\section{SELF-REFLEXIVITY: REWRITING THE BIOGRAPHICAL NARRATIVE}

Part of this reflexive process involved Sipho having to make an important decision of whether to continue with his Commerce degree (as per his family's wishes) or to take a risk (against his family's wishes) and register in the Humanities faculty for a degree in Drama, which he 
admitted, was where his passion actually lies. This is something he had previously kept hidden, for fear of being ridiculed, especially when measured against the high status that a Commerce degree held in the township setting. In weighing up his options he reflected in a very particular way on how his passion for learning and acting was nurtured, and recalled the inspiration he drew from his teachers who 'performed' and used 'entertainment' in their teaching (Sipho Interview). This type of reflexivity enabled him to make the decision to do Drama. This selfreflective engagement is important, as it allows for the 'ordering of self-narratives' (Giddens 1991, 244) in such a way that the routine nature of everyday life and the stability and sense of continuity of the self that it creates can once again be restored. Coupland, Nussbaum and Grossman summarise Giddens’s point as follows:

For Giddens, 'the self' must be seen as the focus of an ongoing dialogue that individuals sustain with themselves in relation to their changing life experiences ... any account of who we are will need to respond to continuously evolving circumstances and how we align ourselves in relation to them (1993, XIV).

In Sipho's case, the consequences of his decision to study Drama turned out to be quite positive. In fact, it changed his outlook on life and transformed his sense of location in the world. Fateful moments must therefore be viewed in line with the consequences of the decisions which individuals make at the time of their fateful encounters. The consequences of fateful decisions carry with them the possibilities for transforming and renewing the self. In Sipho's case, his decision to leave Commerce and to do Drama was a fateful one, in that it changed his life. He excelled in Drama and collected a number of accolades along the way, including various local and international awards, and he even made a few television appearances. Sipho was therefore able to restore the shattered cocoon through interpreting his failure in Commerce in light of his success in Drama. Such success allowed him to validate his choice to do Drama, where he found a home for his 'capital' (I draw here on Bourdieu and Wacquant's 1992 analysis of 'capital' as something that has value in terms of how individuals are located socially, politically, culturally and economically). Sipho's fateful moment experience in Commerce signalled a clash between the types of capital he possessed (in terms of home, school, culture) and the types of capital that Commerce required and valued. In Drama he was able to draw on his own capital in direct and creative ways to inform the learning process. This type of agency enabled him to turn his undervalued capital into gain, in a productive, meaningful and affirming way. In doing so he reconnected with his home and with those who made him feel whole, thus re-establishing a sense of trust and authenticity within himself, to the extent that he could then reflect on his academic achievement as something that was set in motion when he was still at primary school: 
My mother was so excited when one of my teachers told her 'look after that boy, there's something there'. There's a sense of greatness I feel about myself, having risen from poverty stretches [one] ... In those situations one thing that pulled me through was that sense of greatness, there's something, something great in store for me (Sipho Interview).

I have blisters [on] my legs but I'm continuing with the race ... I don't think of myself as someone from now ... I think of myself as I'm a continuation of people (Sipho interview).

These extracts illustrate Sipho’s revision of his 'biographical narratives’ (Giddens 1991, 5) in which he reconstructed facets of his life in relation to continually occurring events. Through this reflexive process he repaired his damaged cocoon. His ability to experience continuity in identity is indicative of an achieved state of ontological security and an emerging authentic sense of self. It is this emerging self that Sipho must now nurture.

\section{BUILDING A RESILIENT SELF: ACQUIRING LEGITIMACY THROUGH DEVELOPING THE 'RIGHT TO SPEAK'}

As part of this nurturing and sustaining of self, Sipho had to acquire defence mechanisms to make his protective cocoon more resilient. Although his entry into university had been marked by a process of alienation, dislocation, silence and failure, he managed, as a result of his fateful moment experience in Commerce, to renegotiate, relocate and redefine himself as someone who has value and who belongs in the institution. Through the process of reconciling his home and university identities, he possessed an updated autobiographical narrative that reflected his status as a successful black working class, first generation Drama student. In other words he successfully developed 'a right to speak' and thereby 'commands reception' (Pierce 1995). He defined his transition and the possibilities that this held in store for him, as follows:

Drama gives me the physical ability to recreate myself ... for example, playing somebody else ... that I'm not everyday but ... that I might be inside (Sipho interview).

However, as can be seen from Sipho’s experiences in some of the other Humanities courses he took, he still struggled with the lack of acknowledgement and authenticity afforded to those like him in the classroom. This is especially evident in his encounters with his History lecturers:

They [lecturers] always refer to the Xhosa people and me as a Xhosa person in the class I would say: 'me, us' ... there was this constant way of being pushed to be objective about this, and for me, I'm like no, but then you talking about my people's history, you talking about people in the township, you not talking about 'them', you're talking about 'me', you have one of 'them' inside the room ... but you realize that those things are still taken for granted ... that even you, when you write you are not expected to come from your home (Sipho interview). 
This extract illustrates Sipho's sense of frustration and alienation as he navigated from the security and stability in Drama to other spaces within the academic setting where his capital continued to be undervalued. The lack of recognition of Sipho as a real, live subject of discussion in the History class created a barrier to learning and served 'to increase [his] conceptions of isolation and alienation' (Read et al. 2003, 271). This sense of othering experienced by Sipho resonates with the experiences of many marginalised and non-traditional students who remain subject to the dominant discourses of higher education: 'to a large extent they continue to be constrained by these discourses ... and also by a relative lack of material and cultural resources' (Read et al. 2003, 268-269). Sipho’s experiences of being rendered absent in the classroom forced him to aggressively validate and account for his own presence, or face being silenced by the dominant institutional discourse. His experiences in the History classes illustrate the extent to which he was left with the choice of towing the line, or to become the subject of severe scrutiny when he challenged dominant perceptions. Giddens $(1991,114)$ reminds us that in situations such as these where high levels of personal conflict prevail, we are called upon to constantly monitor our levels of participation in this 'climate of risk'. Within such a 'climate of risk' the stakes are raised all the time. This gives rise to 'new mechanisms of self identity' in which individuals engage in a dynamic manner with 'social influences' which determine, but which in turn are also determined by their actions (Giddens 1991).

Sipho's reaction to what was happening in his History classes was, therefore, an indication of just how strong and resilient his protective cocoon was becoming, since his fateful moment in Commerce. His groundedness and mastery in Drama nurtured a much stronger and confident sense of self, and empowered him to confront the challenges he encountered elsewhere. By challenging his lecturers, he showed a much stronger resolve than when he first arrived at university. He came to assert his need to stand up and to be counted as relevant and as a legitimate entity within his classes. There was an active attempt here to bring his home - that sense of home whose legitimacy and value he had come to reconceptualise, recapture and reaffirm in light of his fateful moment experience - into the university setting. Having lost sight of his home in Commerce, and by extension, his authentic sense of self, he then set out actively to reclaim that identity within the curriculum. In his History classes he therefore provoked the silences surrounding his origins. He spoke his origins into existence as a way of concretising the curriculum's references to a removed and abstract self. Sipho's claim that 'when you write you are not expected to come from your home' is not something that rendered him silent here, the way it did in Commerce. Nor did this claim pose any serious threat to the ontological security of a new evolving self. On the contrary, it served as a catalyst for action in which the 
possibilities for change and for new ways of being in the world were borne.

Sipho's story illustrates that the great challenge for non-traditional and working class students who are searching for a sense of belonging, is how to balance academic success without 'losing yourself' in the process (Reay 2001, 341). Sipho's dilemma in realising that 'when you write you are not expected to come from your home' speaks strongly to the challenge he faced of trying to hold on to a true sense of self while fending off the constant threat of becoming assimilated into dominant institutional discourses where he would have no option but to comply with 'the way we do things around here' (Jansen 2004, 1). A vital part of Sipho’s transformation of self, therefore, was that his sense of home is realised in Drama, and this feeling of being 'at home' created possibilities for realising a new and transformed self, a sense of self that was becoming increasingly strong and robust within a protective cocoon that was growing in durability and resilience. His fateful moment experience in Commerce therefore leads to a lifechanging decision to follow his dream of studying Drama, and it is in this process of transitioning into Drama that he locates a sense of authenticity. He had developed an 'academic' identity (Vincent and Idahosa 2014, 1444) and was now an active and successful participant in his own education. Aided by his dramatic discourse he soon learnt how to critically interrogate his identity as a first generation working class Xhosa student attending a historically white university. The battles he fights in his other courses such as History, comes about as a result of his critique of the ways in which blackness and black realities continue to be devalued. But the fact that he is able to withstand this onslaught on black identity and challenge it to the extent that he does, is indicative of the fact that he now possesses a strong and resolute self that seeks to make its presence felt, unapologetically. Sipho knows he has changed in a fundamental way and that he cannot go back to the way he was before. The sense of legitimacy that Sipho claimed within the university was thus intricately linked to claiming an authentic self, which in turn promotes his academic success (Vincent and Idahosa 2014, 1444). Transformation in this sense is indicative of 'persons in process' (Herrington 2000).

\section{DISCUSSION: AGENCY, REFLEXIVITY AND THE ROUTINE NATURE OF 'BEING'}

Sipho's experience of university illustrates how the ability to develop a sense of belonging works best when the institutional culture complements or at least acknowledges students' backgrounds (see Mann 2008 for insight into this). His narrative indicates the extent to which issues of social class, schooling background and constructions of race intersect in ways that reinforce positions of inequality and privilege within the higher education setting. A huge disjuncture between home and university can sometimes lead to traumatic learning experiences 
which can fracture and break through the protective layers surrounding personal identity, resulting in academic underperformance. This breach of personal security can drastically undermine the sense of stability, self-worth, belonging and purpose needed by students to succeed at university. Sipho's experience reveals that the academic setting becomes the space in which the greatest sense of alienation is felt, since it is here where the real differences between 'us' and 'them' with respect to class positions, racial classifications, gender, schooling backgrounds and so forth, and the types of access and privileges that these differences affords one, are realised. Historically white universities represent the gathering point where students from all walks of life converge in increasing numbers to participate in structured curricula that have traditionally catered for an elite white minority. The teaching and learning spaces of the university thus come to represent a microcosm of the broader social order, and as such, create an acute focus on individual bodies and how they relate to others.

Part of the argument presented here is that Black working class students who are confronted with a lack of access into the traditional social networks operating within historically white universities, do not have much of a safety net to fall back on. Without these buffers, the intensity of experiences are increased and students find themselves fully exposed to some of the harsh realities of trying to transition into campus life. In these instances 'fateful moments' signify turning points in individuals' lives. These moments, referred to by Vincent and Idahosa (2014, 1443) as 'catalytic moments', expose vulnerabilities that weaken the sense of self, but it also acts as a powerful reflexive stimulus for ushering in possibilities for remaking a new secure self (also see Mezirow’s 1990 and 1991 studies on how identity transformation takes place through a process of critical reflection). This reflective process constitutes an act of agency, defined by Mann $(2008,12)$ as 'the capacity of the individual to make sense of their own particular circumstances in their own way and in the individual's capacity to transform these'. This ability to enact agency is important for maintaining a necessary element of resilience in our identities. A sense of self that is housed within a protective cocoon that lacks such a measure of resilience will experience a continuous state of traumatic flux, incapable of action, resulting in what Laing $(1965$, cited in Giddens 1991, 53) refers to as 'inner deadness'. This numbing of the self, acts as a barrier to new possibilities of being in the world and renders null and void the element of agency and meaningful interaction in the learning process. Such an individual is completely vulnerable to the risks that threaten any sense of established routine made possible by the 'protective cocoon'. In Sipho's case it is therefore crucial to establish a routine (even if it was one of constantly challenging the curriculum) in the risky academic setting. Such routine constitutes a defensive measure for the protection of the self. Routine helps create familiarity 
with the institutional discourses, and allowed Sipho to gradually learn how 'to play the game' and to ‘act confidently’ (Read et al. 2003, 273; Mann 2008, 50).

\section{CONCLUSION}

The pervasiveness of the historical disadvantages that still impact education cannot only be dealt with in terms of mechanisms for creating access to institutions of higher education. Black, disadvantaged, first generation students must be viewed in terms of their physical and academic presence, but beyond this there also needs to be an appreciation or understanding of how the transition into university affects the ways in which they come to view and acknowledge their presence in these spaces, and the impacts thereof on their sense of self. Here I take seriously Cornell and Kessi’s $(2016,13)$ appeal that:

The university community needs to be conscientized about the experiences of black students and how dominant and institutionalized discourses and practices continue to exclude black students from successful outcomes.

This calls for a re-evaluation of the way in which we deal with issues of student diversity, equity and transformation at institutional and curriculum levels (for a brief illustration see Nomdo 2013, where I unpack the importance of collaborative practices for promoting access and a sense of belonging amongst extended degree students into disciplinary discourses; also see Scott's 2013 insights into issues of equity and curriculum transformation). It is important to recognize that peoples' abilities to adapt to change and to transform, all form part of the dynamics of being culturally and socially situated. As black students increase in numbers at historically white institutions, the ability to adapt, and to achieve recognition and equal status in settings where white achievement is the norm, will continue to be a challenge. Tapping into the experiences of underprepared, non-traditional students who successfully negotiate the transition into university will allow insight into some of the 'dilemmas of self' (Giddens 1991, 190-200) that these students experience in the academy. Such research can reveal much about the levels of emotional insecurities accompanying working class black students into higher education, where they have to compete with peers from privileged backgrounds. By acknowledging fateful moment encounters in students' lives, higher education institutions present themselves as accommodating and supportive teaching and learning environments. This will make transformative agendas within these contexts all the more meaningful. West (1996, 10 cited in Mann 2008, 11) aptly captures the essence of this sentiment by asserting that:

higher education is potentially a space in which to manage and transcend feelings of 
marginalization, meaninglessness and inauthenticity ... in which it is possible ... to compose a new life, a different story and a more cohesive self.

Although it is an important survival strategy, learning to play the game is not enough anymore, as it mainly leaves dominant discourses intact. The game itself needs to be changed and reconceptualised so that all can feel at home, or at the very least, be given a chance to do so. Transformation must remain a dynamic entity in which the possibilities for change at multiple levels can be realised.

\section{REFERENCES}

Bangeni, A. and R. Kapp. 2005. Identities in transition: Shifting conceptions of home by black South African university students. African Studies Review 48(3): 1-19.

Bourdieu, P. and L. Wacquant. 1992. An invitation to reflexive sociology. Chicago: University of Chicago Press.

Cornell, J. and S. Kessi. 2016. Black students' experiences of transformation at a previously 'white only' South African university: A photovoice study. Ethnic and Racial Studies Vol. 0: 1-18. http://www.tandfonline.com/doi/full/10.1080/01419870.2016.1206586 (accessed 22 October 2016).

Coupland, N., J. Nussbaum and A. Grossman. 1993. Introduction: Discourse, selfhood, and the lifespan. In Discourse and lifespan identity, ed. N. Coupland and J. Nussbaum, X-xxviii. California: Sage Publications.

Crenshaw, K. 1995. Mapping the margins: Internationality, identity, politics and violence against women of colour. In Critical race theory: The key writings that informed the movement, ed. K. Crenshaw, N. Gotanda, G. Peller and K. Thomas, 354-383. New York: The New Press.

Croft, S. 2012. Constructing ontological insecurity: The insecuritization of Britain's Muslims. Contemporary Security Policy 33(2): 219-235.

Department of Education. 1997. Education White Paper 3: A Programme for the Transformation of Higher Education. Pretoria: Department of Education.

Giddens, A. 1991. Modernity and self-identity: Self and society in the late modern age. California: Stanford University Press.

Herrington, A. 2000. Persons in process: Four stories of writing and personal development in college. Urbana, Ill: National Council of Teachers of English.

Hawkes, T. 1977. Structuralism and semiotics. London: Routledge.

Jansen, J. 2004. 'How far have we come?' Mail and Guardian 19 August: 1-5.

Kapp, R. 2000. 'With English you can go everywhere': An analysis of the role and status of English at a former DET school. Journal of Education 25: 227-259.

Kapp, R. 2001. 'Stretching across boundaries': A discussion of writing and identity in an academic literacy course at the University of Cape Town. Paper presented at the International Literacy Conference, November, Cape Town.

Luckett, K. and T. Luckett. 2009. The development of agency in first generation learners in higher education: A social realist analysis. Teaching in Higher Education 14(5): 469-481.

MacGregor, K. 2009. South Africa: Communist takes charge of higher education. University World News: The global window on higher education, Issue 0077, 24 May. http://universityworldnews. com/article.php?story=20090521180301622 (accessed 6 July 2009).

Mann, S. 2008. Study, power and the university. England: Society for Research into Higher education 
\& Open University Press.

Mbatha, P. 2015. 'Luister: Racism at Stellenbosch University’. The Citizen. http://connect.citizen.co.za/ 15907/luister-racism-at-stellenbosch-university/ (accessed 1 September 2015).

Mezirow, J. 1990. Fostering critical reflection in adulthood. San Francisco: Jossey-Bass Publishers.

Mezirow, J. 1991. Transformative dimensions of adult learning. San Francisco: Jossey-Bass Publishers.

Nkosi, B. 2015. 'This is the year varsities will transform - Blade'. Mail \& Guardian Online. http://mg.co.za/article/2015-05-14-this-is-the-year-varsities-will-transform-blade (accessed 1 September 2015).

Nomdo, G. 2006. Identity, power and discourse: The socio-political self-representations of successful 'black' students. In Academic literacy and the languages of change, ed. L. Thesen and E. van Pletzen, 180-206. London: Continuum Press.

Nomdo, G. 2013. Collaborating by design: Language embedded in an Economics course. In Surfacing possibilities: What it means to work with first generation higher education students, ed. J. Pym and M. Paxton, 100-122. Illinois, USA: Common Ground Publishing LLC.

Nomdo, G. 2015. At the crossroads of the identity (re)construction process: An analysis of 'fateful moments' in the lives of Coloured students within an equity development programme at UCT. $\mathrm{PhD}$ dissertation, University of Cape Town, Cape Town. https://open.uct.ac.za/bitstream/ handle/11427/16649/thesis_hum_2015_nomdo_gideon_john.pdf?sequence=1 (accessed 25 November 2016).

Peirce, B. N. 1995. 'Social identity, investment, and language learning’. TESOL Quarterly 29: 9-31.

Pym, J. and R. Kapp. 2011. Harnessing agency: Towards a learning model for undergraduate students. Studies in Higher Education 1: 1-12.

Pym, J. and M. Paxton. (Eds.). 2013. Surfacing possibilities: What it Means to Work with First Generation Higher Education Students. Illinois, USA: Common Ground Publishing LLC.

Read, B., L. Archer and C. Leathwood. 2003. Challenging cultures? Student conceptions of 'belonging' and ‘isolation’ at a post-1992 university. Studies in Higher Education 28(3): 261-277.

Reay, D. 2001. 'Finding or losing yourself? Working-class relationships to education'. Journal of Education Policy 16(4): 333-346.

Scott, I. 2013. Paving the way for systemic change: Curriculum change for development and equity. In Surfacing possibilities: What it means to work with first generation higher education students, ed. J. Pym and M. Paxton, 14-25. Illinois, USA: Common Ground Publishing LLC.

Scott, I., N. Yeld and J. Hendry. 2007. A case for improving teaching and learning in South African higher education. Higher Education Monitor 6. Pretoria: The Council on Higher Education.

Shotter, J. 1993. Becoming someone: Identity and belonging. In Discourse and lifespan identity, ed. N. Coupland and J. Nussbaum, 5-27. California: Sage Publications.

Terre Blanche, M. and K. Durrheim. 1999. Social constructionist methods. In Research in practice, ed. M. Terre Blanche and K. Durrheim, 147-172. Cape Town: UCT Press.

Thaver, L. 2006. 'At home', institutional culture and higher education: Some methodological considerations. Perspectives of Education 24(1): 15-26.

The Daily Maverick. 2015. Open Stellenbosch: A university education in exclusion. eNews Channel Africa. $\quad$ http://www.enca.com/opinion/open-stellenbosch-university-education-exclusion (accessed 28 August 2015).

The Ministerial Committee on Transformation in Higher Education. 2008. Report of the Ministerial Committee on Transformation and Social Cohesion and the Elimination of Discrimination in Public Higher Education Institutions. Pretoria: Department of Education.

UCT News. 2015. 'Transform UCT'. http://www.uct.ac.za/news/Transform-UCT/ (accessed 2 July 2015).

Wheeler, M. 2013. Martin Heidegger. In The Stanford Encyclopaedia of Philosophy, ed. E. Zalta. 
http://plato.stanford.edu/archives/spr2013/entries/heidegger/ (accessed 8 October 2013).

Woods, P. 1993. Critical Events in Education. British Journal of Sociology of Education 14(4): 355371.

Vincent, L. and G. Idahosa. 2014. 'Joining the academic life': South African students who succeed at university despite not meeting standard entry requirements. South African Journal of Higher Education 28(4): 1433-1447.

Zuma, B. 2013. The social psychology of self-segregation: The case of university student friendship groups. Doctoral Thesis, Department of Psychology, University of Cape Town. https://open.uct.ac.za/bitstream/item/11348/thesis_hum_2013_zuma_b.pdf?sequence=1 (accessed 16 November 2015). 